\title{
ARTHROSCOPY OF THE KNEE IN RHEUMATIC DISEASES
}

\author{
BY \\ M. I. V. JAYSON*† AND A. ST. J. DIXON* \\ From the Royal National Hospital for Rheumatic Diseases, Bath*, and Bristol Royal Infirmary†
}

The principle of viewing body cavities via optical instruments has been applied to many areas of the body and procedures such as sigmoidoscopy, gastroscopy, bronchoscopy, cystoscopy, etc., are now commonplace and routine investigations.

Bircher (1922) employed a Jacobaeus laparoscope to examine the interior of joints distended with gas and Burman, Finkelstein, and Mayer (1934) employed an arthroscope in assessing mainly orthopaedic conditions of joints. Arthroscopy has been the subject of considerable research in Japan (Watanabe, Takeda, and Ikeuchi, 1957) and it is perhaps surprising that we have been unable to find any report of systematic studies using this technique in Western literature.

The arthroscope will allow "direct inspection of synovium and cartilage and photography of any important areas. Biopsies can be taken under direct vision which is a great advantage in diagnosing and assessing the severity of different types of arthritis.

\section{The Arthroscope}

The arthroscope set consists of a trochar and sheath which is $6 \mathrm{~mm}$. in diameter, and two telescopes, one for end-viewing with a separate light source and the other for viewing at $90^{\circ}$ to the axis of the instrument with an integral light source. The light bulb is positioned close to the internal lens of each telescope and is connected to a transformer, the voltage of which can be varied, 6 volts being normally required for adequate illumination. The eye-piece of the telescope can be connected to the body of a single lens reflex camera for photographic purposes. The shutter of the camera is also coupled to the transformer, so that the voltage is automatically stepped up to 15 volts for the moment when a photograph is taken, so that a flash effect is obtained. A separate but smaller trochar and cannula are provided through which a biopsy forceps can be passed.

\section{Method of Arthroscopy}

The optical parts of the arthroscope are sterilized chemically and the rest by autoclaving.

The investigation is performed with full sterile precautions in an operating theatre. It is often helpful to position the knee in about $5^{\circ}$ of flexion. By careful palpation the site for entry of the arthroscope is decided; this is usually below the patella just lateral to the patella ligament, but sometimes it is easier to enter the suprapatellar pouch.

The skin is cleaned and sterilized and covered with sterile adhesive polythene ("Steri-Drape"). Complete towelling is carried out so that only the small area selected for entry of the instrument is left exposed. The skin and deep structures down to the synovium are infiltrated with 1 per cent. lignocaine. If the joint is not already distended with fluid, $50 \mathrm{ml}$. normal saline are injected into the joint by a needle passed through the anaesthetized area. A longitudinal incision through the skin, about a quarter of an inch long, is made with a scalpel.

Entry into the Joint.-The trochar and cannula are carefully advanced using a rotary movement through this incision and through the infra patellar fat pad into the synovial space. It is immediately apparent when the space has been punctured as no pressure is then required to advance the instrument. The trochar is removed and the direct light source followed by the end-viewing telescope is passed down through the cannula and locked into place. Much of the fluid within the joint escapes during these procedures. The side-arm of the cannula is connected to a drip set, and normal saline or 0.18 per cent. saline $/ 4 \cdot 3$ per cent. dextrose at room temperature is allowed to re-distend the joint. The sterile lead from the transformer is connected to the arthroscope and by looking through the telescope it is then possible to study the lining of the joint (Fig. 1, overleaf). The voltage of the transformer is adjusted so as to give the appropriate lighting. If the fluid contents of the knee are opalescent it may be necessary to drain and redistend the joint two or three times to obtain a clear view. After inspection with the end-viewing telescope is completed, the sideviewing telescope is inserted. 


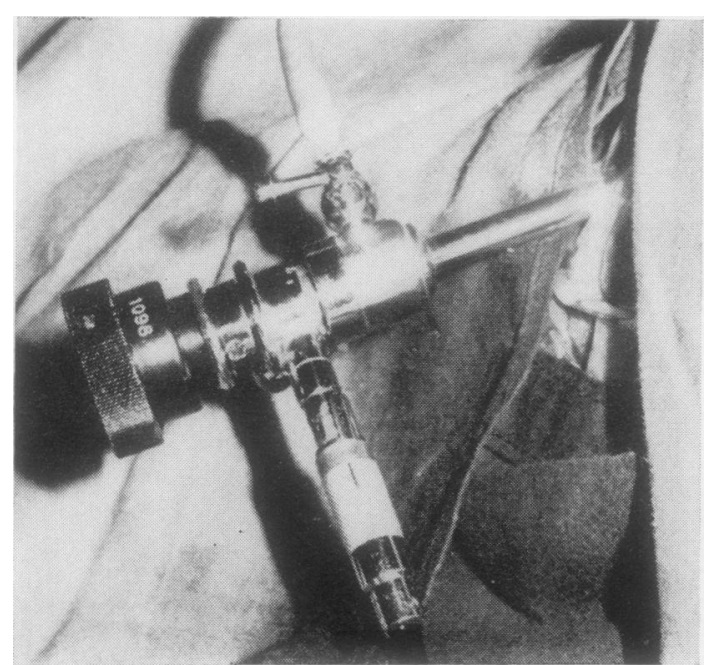

Fig. 1.-The arthroscope in position in the knee joint.

Observation.-The telescope can be easily passed between the patella and the lower end of the femur to observe the cartilage surfaces and then into the suprapatellar pouch so as to see the synovium. The tip of the instrument is carefully moved around the synovium starting from the lateral side and sweeping round to the medial side of the pouch. Careful withdrawal of the instrument allows the anterior part of the femoro-tibial joint to be inspected, and if the knee is flexed at $90^{\circ}$ the instrument may be passed deeper into this joint. However it has not been possible to observe the semilunar cartilages, the cruciate ligaments, and the femoro-tibial articulation under local anaesthesia, and general or spinal anaesthesia would be required in order to manipulate the knee into the ideal position. When satisfactory views have been obtained, the camera can be attached and photographs taken through the telescope.

Biopsy.-There are two methods of obtaining the biopsy. The first is by pointing the telescope directly at the area of interest. The telescope and light source are withdrawn and the biopsy forceps inserted directly through the sheath and the biopsy is taken from this site. This has the advantage of not requiring a second incision, but also the disadvantage that the site of biopsy is not seen at the moment that the specimen is taken so that it is possible to miss the area of primary importance. Alternatively, an area of skin may be anaesthetized on the lateral side of the supra patellar pouch; a second incision is then made through which the smaller trochar and cannula are inserted into the superior pouch. The trochar is then removed and the biopsy forceps inserted in its place. By looking through the telescope it is now possible to see the biting end of the forceps, and, by manipulating the handle of this instrument, suspected areas can be biopsied.

Completion of Procedure.-At the end of the study the telescope is removed and all fluid drained from the joint, after which the sheath is removed. One stitch is required at the site where the larger trochar and cannula have been inserted, but is not usually necessary for the incision made for the small biopsy trochar.

A firm dressing is applied to the knee and after resting in bed for 24 hours the patient is allowed to walk normally and may be discharged from hospital. The stitch is removed after 10 days.

\section{Results of Investigations}

A series of 23 arthroscopies has been performed to date. Adequate inspection was obtained in all but two. Both these patients had hot swollen knees and the examination was discontinued because of pain. The majority of the other patients found the procedure completely painless, but a few experienced mild discomfort. A number of patients have insisted that their knees were improved after the procedure. It is not intended to claim that this procedure is of therapeutic benefit, but it is worth recalling that, before the modern era, irrigation of the knee joint with saline was one form of treatment for rheumatoid arthritis. Burman, Finkelstein, and Mayer (1934) also noticed a similar improvement after arthroscopy.

There have been no instances of infection or of any other unpleasant after-effects of the procedure.

The 23 patients studied and the results of the investigations are shown in the Table.

TABLE

RESULTS OF INVESTIGATIONS IN 23 PATIENTS

\begin{tabular}{c|c|c}
\hline $\begin{array}{c}\text { Patient } \\
\text { No. }\end{array}$ & Disease & \multicolumn{1}{c}{ Arthroscopic Findings } \\
\hline 1 & $\begin{array}{c}\text { Acute large joint arthritis; aetiology } \\
\text { unknown }\end{array}$ & Examination discontinued as too painful \\
\hline 2 & $\begin{array}{l}\text { Osteoarthrosis with intermittent lock- } \\
\text { ing }\end{array}$ & $\begin{array}{l}\text { No loose bodies seen } \\
\text { Profuse synovial villi with discrete vasculat markings }\end{array}$ \\
\hline 3 & $\begin{array}{l}\text { Psoriatic arthritis with locking } \\
\text { Coarse red fronds of synovium } \\
\text { No discrete vascular pattern } \\
\text { Pock-marked articular cartilage } \\
\text { No loose body seen }\end{array}$ \\
\hline 4 & $\begin{array}{l}\text { Osteoarthrosis secondary to old frac- } \\
\text { ture of medial tibial condyle }\end{array}$ & $\begin{array}{l}\text { Smooth pale synovium with discrete vascular pattern } \\
\text { Multiple fibrin deposits }\end{array}$ \\
\hline
\end{tabular}


TABLE (continued)

\begin{tabular}{|c|c|c|}
\hline $\begin{array}{l}\text { Patient } \\
\text { No. }\end{array}$ & Disease & Arthroscopic Findings \\
\hline 5 & $\begin{array}{l}\text { Rheumatoid arthritis, chronic but } \\
\text { acute exacerbation } \\
\text { Loose body on } X \text { ray above patella }\end{array}$ & $\begin{array}{l}\text { Smooth uniformly red synovium spreading over femoral condyles } \\
\text { Pitting of patella cartilage } \\
\text { White fixed chondrosis superior to patella, removal attempted, but failed }\end{array}$ \\
\hline 6 & $\begin{array}{l}\text { Rheumatoid arthritis } \\
\text { Knee effusion }\end{array}$ & $\begin{array}{l}\text { Synovium showing very patchy change-mainly normal, but areas with large smooth } \\
\text { red polypi } \\
\text { Pannus over femoral condyles }\end{array}$ \\
\hline 7 & Active chronic rheumatoid arthritis & $\begin{array}{l}\text { Synovium shows areas of large polypi with some relatively normal areas } \\
\text { Cartilage very pitted and irregular }\end{array}$ \\
\hline 8 & $\begin{array}{l}\text { Recurrent hydrarthrosis of knees, } \\
\text { cause unknown }\end{array}$ & $\begin{array}{l}\text { Large smooth red polypi } \\
\text { Mass of fine villi } \\
\text { Band of fibrin } \\
\text { Appearances suggested rheumatoid arthritis, confirmed by biopsy }\end{array}$ \\
\hline 9 & $\begin{array}{l}\text { Rheumatoid arthritis } \\
\text { Knee effusion } \\
\text { ? For Surgery }\end{array}$ & $\begin{array}{l}\text { Synovium shows numerous large smooth rounded polypi; below the patella these } \\
\text { have superficial vascular markings, but are uniformly red in the suprapatellar } \\
\text { pouch } \\
\text { Multiple fine villi with vessels }\end{array}$ \\
\hline 10 & $\begin{array}{l}\text { Post-synovectomy for rheumatoid } \\
\text { arthritis } \\
\text { Recurrent effusion } 2 \text { years after surgery }\end{array}$ & $\begin{array}{l}\text { Synovium partly normal and partly showing burnt-out rheumatoid arthritis with areas } \\
\text { of pigmentation and loss of vascular pattern } \\
\text { Pannus over femoral condyles } \\
\text { Irregular patellar cartilage } \\
\text { Masses of fibrin }\end{array}$ \\
\hline 11 & Recurrent knee pain & $\begin{array}{l}\text { Chondromalacia of patella, with mass of multiple fine leaf-like villi and areas with } \\
\text { short stubbly villi }\end{array}$ \\
\hline 12 & Early rheumatoid arthritis & $\begin{array}{l}\text { Hypertrophied erythematous synovium with multiple translucent leaf-like villi with } \\
\text { vessels, some tightly coiled }\end{array}$ \\
\hline 13 & Osteoarthrosis of knee with locking & $\begin{array}{l}\text { Synovium smooth and pale with discrete vessels and short stubbly villi } \\
\text { Areas with diminished vascular pattern } \\
\text { Some hypertrophy in intrapatellar pouch with leaf-like villi with fine vessels } \\
\text { No loose bodies seen }\end{array}$ \\
\hline 14 & $\begin{array}{l}\text { Rheumatoid arthritis, acute exacer- } \\
\text { bation }\end{array}$ & $\begin{array}{l}\text { Smooth erythematous synovium with no discrete vascular pattern } \\
\text { One large smooth uniformly red polyp } \\
\text { Large clumps of fibrin }\end{array}$ \\
\hline 15 & $\begin{array}{l}\text { Rheumatoid arthritis, chronic with } \\
\text { boggy synovium }\end{array}$ & $\begin{array}{l}\text { Numerous large smooth uniformly pale interlacing fibrin bundles } \\
\text { Synovium diffusely red with no discrete vessels }\end{array}$ \\
\hline 16 & $\begin{array}{l}\text { Rheumatoid arthritis } \\
\text { Gross synovial hypertrophy }\end{array}$ & Examination too painful \\
\hline 17 & $\begin{array}{l}\text { Osteoarthrosis with occasional lock- } \\
\text { ing }\end{array}$ & $\begin{array}{l}\text { No loose body seen } \\
\text { Numerous fine villi with discrete vessels } \\
\text { Synovium otherwise normal }\end{array}$ \\
\hline 18 & Rheumatoid arthritis & $\begin{array}{l}\text { Synovium smooth and erythematous with vascular pattern just visible in suprapatellar } \\
\text { pouch } \\
\text { Mass of fine villi and one large smooth uniformly red polyp below patella } \\
\text { Roughened patellar cartilage } \\
\text { Clumps of fibrin }\end{array}$ \\
\hline 19 & $\begin{array}{l}\text { Polymyalgia rheumatica } \\
\text { Developed knee effusions }\end{array}$ & $\begin{array}{l}\text { Mass of small club-shaped villi with fine vessels in suprapatellar pouch and behind } \\
\text { patella. Large polypi without discrete vessels behind patella and in suprapatellar } \\
\text { pouch } \\
\text { Synovial wall shows patchy brown pigmentation } \\
\text { Patellar cartilage rough and irregular } \\
\text { Appearances suggest rheumatoid arthritis with osteoarthrosis of patella } \\
\text { Rheumatoid arthritis confirmed by biopsy }\end{array}$ \\
\hline 20 & $\begin{array}{l}\text { Chronic rheumatoid arthritis with } \\
\text { flexion contracture }\end{array}$ & $\begin{array}{l}\text { Thick white synovium } \\
\text { No vascular pattern } \\
\text { Masses of fibrin }\end{array}$ \\
\hline 21 & $\begin{array}{l}\text { Persistent pain on antero-medial } \\
\text { aspect of knee, cause unknown }\end{array}$ & $\begin{array}{l}\text { Irregularity of cartilage over medial femoral condyle } \\
\text { Early osteoarthrosis }\end{array}$ \\
\hline 22 & Sero-negative rheumatoid arthritis & $\begin{array}{l}\text { Diffusely erythematous synovium throughout joint } \\
\text { Villous proliferation in anterior part of femoro-tibial joint }\end{array}$ \\
\hline 23 & Monoarticular arthritis & $\begin{array}{l}\text { Diffusely erythematous synovium } \\
\text { Gross proliferation of villi and polypi in posterior wall of suprapatellar bursa and } \\
\text { behind patella } \\
\text { Appearances suggest acute rheumatoid arthritis }\end{array}$ \\
\hline
\end{tabular}



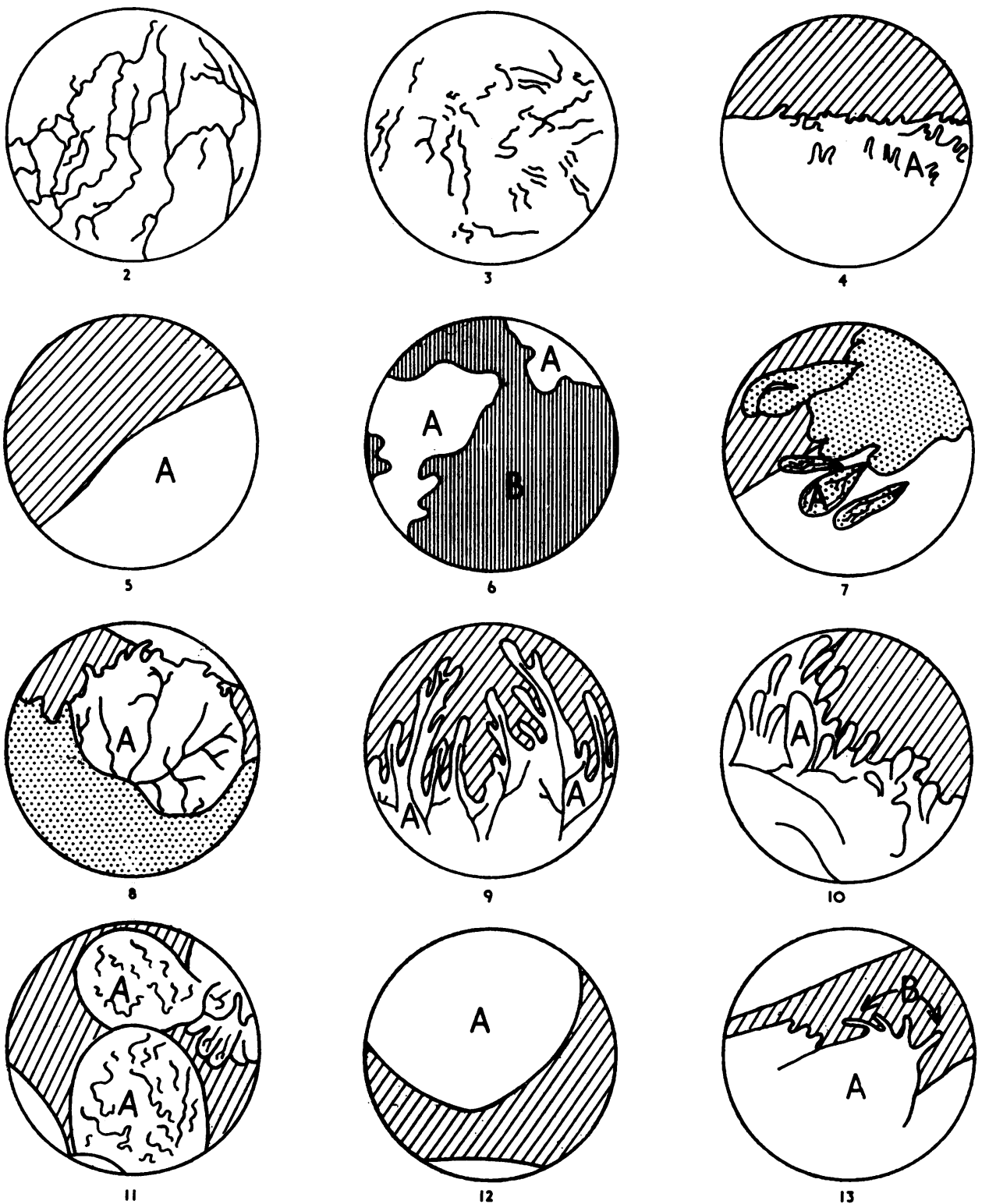

Fig. 2.-Normal synovium-marked vascularity.

Fig. 3.-Normal synovium-poor vascularity.

Fig. 4.-Normal synovium with very tiny stubbly villi (A) in osteoarthritis.

Fig. 5.-Early rheumatoid arthritis. Diffusely red synovium (A). Individual vessels no longer visible.

Fig. 6.- Inactive rheumatoid arthritis. Pale mucosa (A) without vessels and with brown pigmentation (B).

Fig. 7.-Normal synovium. Fine transparent villi (A) attached to infrapatellar fat pad.
Fig. 8.-Rheumatoid arthritis. Leaf-like villi (A) with branching vessels.

Fig. 9.-Rheumatoid arthritis. Multiple villi (A) with vessels.

Fig. 10.-Osteoarthrosis. Shorter finger-like villi (A).

Fig. 11.-Rheumatoid arthritis. Large rounded polypi (A) with fine superficial capillary network.

Fig. 12.-Rheumatoid arthritis. Large smooth diffusely red polypus
(A).

Fig. 13.-Rheumatoid arthritis. Large polypus (A) with secondary villi (B). 
ARTHROSCOPY OF THE KNEE JOINT IN RHEUMATIC DISEASES
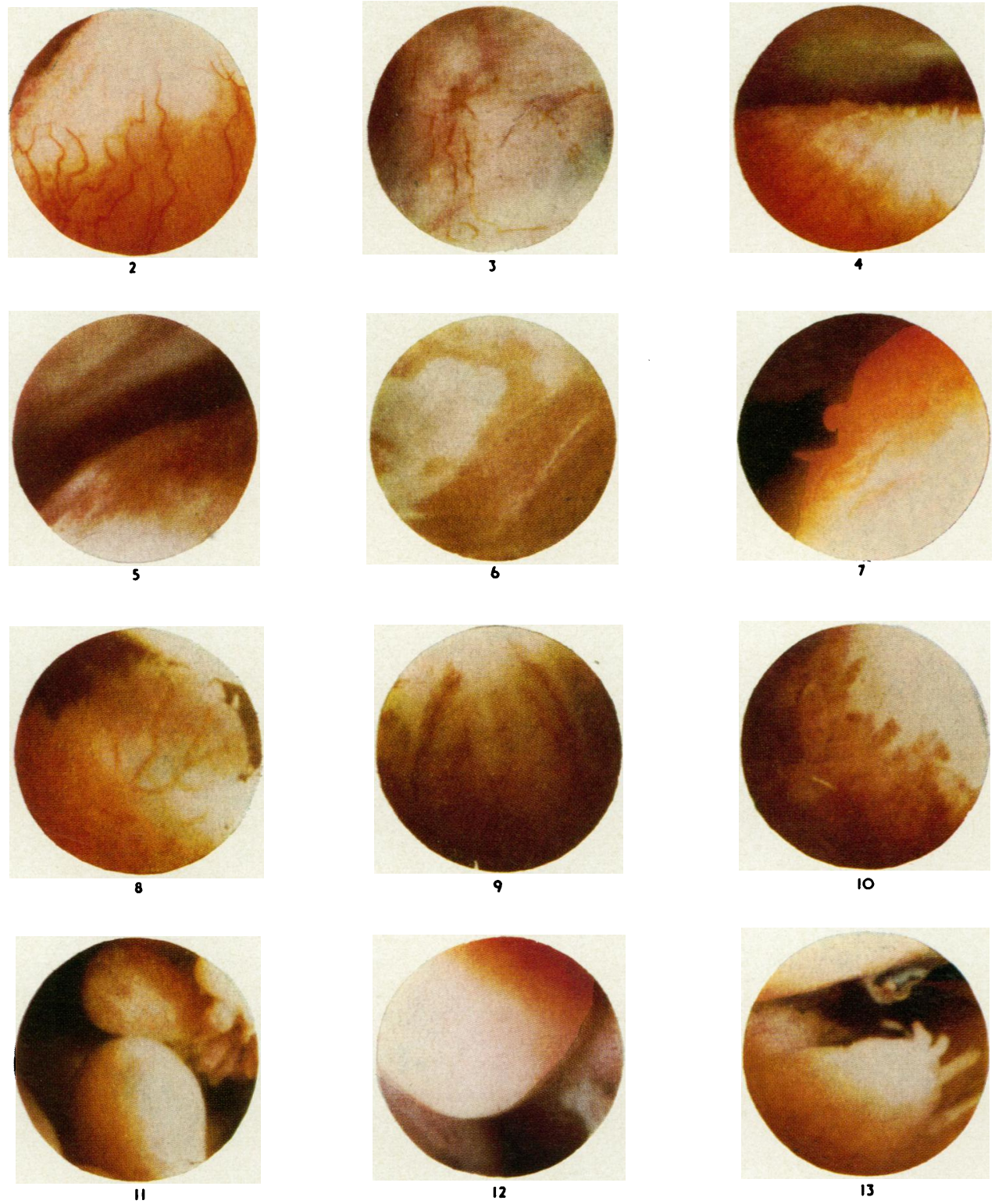
The patchy distribution of abnormalities is a very striking feature. The finding of Palmer (1967) that the main villous bearing areas of synovium within the knee are the posterior surface of the suprapatellar bursa and around the edges of the patella is confirmed, and these areas, especially the synovium overlying the infrapatellar fat pad, tend to be the first sites of pathological changes.

The normal synovium is very pale in colour and the superficial vascular anastomotic plexus is clearly visible through the arthroscope. The appearances resemble the pictures of Barnett, Davies, and MacConaill (1961) obtained by injecting the vessels with indian ink. The normal range of vascularity is illustrated in Figs 2 and 3, being marked in the former and much less in the latter; these are normal areas in arthritic knees and correspond to appearances found in normal cadaver knees.

An essentially similar picture is seen in patients with degenerative joint disease, except that very short stubbly villi may be seen standing up on the surface of the synovium (Fig. 4A).

In early rheumatoid arthritis (Fig. 5) affected parts of the synovium appear granular or diffusely erythematous (Fig. 5A) and it may no longer be possible to see the individual synovial vessels. In late burnt-out rheumatoid arthritis (Fig. 6) there is complete loss of the vascular pattern. The mucosa is pale (Fig. 6A) but patches of brown pigmentation (Fig. 6B) may be seen on the surface. This brown pigmentation is thought to be due to deposits of haemosiderin.

Tiny transparent villi (Fig. 7A) are normally seen to be attached to the infrapatellar fat pad. Larger leaf-like villi (Figs 8A, 9A) may be seen in normal knees but can also be seen in greatly increased numbers in both osteoarthrosis and rheumatoid arthritis. Blood vessels are present and branching systems may be observed (Fig. 8A). These vessels may be very tightly coiled in rheumatoid arthritis. Shorter, less slender, finger-like villi (Fig. 10A) are also seen in both rheumatoid and osteoarthritis, but not attached to normal synovium.

In patients with more advanced rheumatoid arthritis and a thick synovium, much larger rounded polypi may be found (Figs 11, 12, 13). Fine capillaries may be present on the surface of these polypi (Fig. 11A), and in others (Fig. 12A) the surface is diffusely red with no distinct vessels. Some polypi may show secondary villi (Fig. 13B) as tiny stubbly excrescences. Other large polypi may fuse to form bridges (Fig. 14A).

Pannus can be seen as proliferated synovium. In Fig. 15 the patellar cartilage (Fig. 15A) is seen to be overlapped by a mass of hypertrophied diffusely red synovium (Fig. 15B). Fig. 16 shows the medial tibial condyle (Fig. 16A) surrounded by interlacing bundles of proliferated synovium (Fig. 16B) with some fibrin above (Fig. 16C). Occasionally pannus may be seen spreading forward like a sheet (Fig. 17A) over the cartilage (Fig. 17B).

Normal cartilage (Fig. 18A) is absolutely smooth, but in osteoarthrosis (Fig. 19A) the surface becomes rough and irregular. More advanced osteoarthrosis has not been studied because of difficulties encountered in inserting the instrument into a narrow joint space. The patello-femoral articulation can be seen as a whole in Fig. 20, in which there is slight roughening of the cartilage on the patella (Fig. 20A) and on the dorsal surface of the femoral condyles (Fig. 20B) with early pannus (Fig. 20C) between them. Fig. 21 shows an early erosion. The cartilage (Fig. 21A) on the femoral condyle has a localized area of inflamed pannus (Fig. 21B) and attached to this superficially is fibrin (Fig. 21C). Cartilage may also demonstrate localized areas of abnormality as in Fig. 22, which shows chondromalacia patellae.

Fibrin may adopt a variety of appearances. It may appear as bulky masses (Fig. 23A) and fine connecting threads may be seen (Fig. 23B). These threads may be artefacts produced when the joint is distended by the simulated effusion. Broad bands of dense fibrin (Fig. 24) may be seen attached to the synovial wall or the fibrin may take form of interlacing white structureless bundles (Fig. 25).

Fig. 26 shows a typical biopsy appearance from a patient with rheumatoid arthritis. Synovial polypi are shown in section and demonstrate marked vascularity with perivascular accumulations of lymphocytes and plasma cells shown in more detail in Fig. 27. Fig. 28 illustrates a villus from a patient with rheumatoid arthritis; the accumulation of plasma cells around capillaries can again be seen.

\section{Discussion}

The diagnosis and assessment of rheumatoid arthritis presents many difficulties. In particular the place of early synovectomy in acute rheumatoid arthritis is difficult to define. Double-blind controlled trials are being performed in order to determine whether surgery is of objective benefit. However, a major problem in any patient lies in assessing the degree of synovial hypertrophy and the amount of damage to cartilage and bone. In some patients there is a proliferative type of synovitis which may 

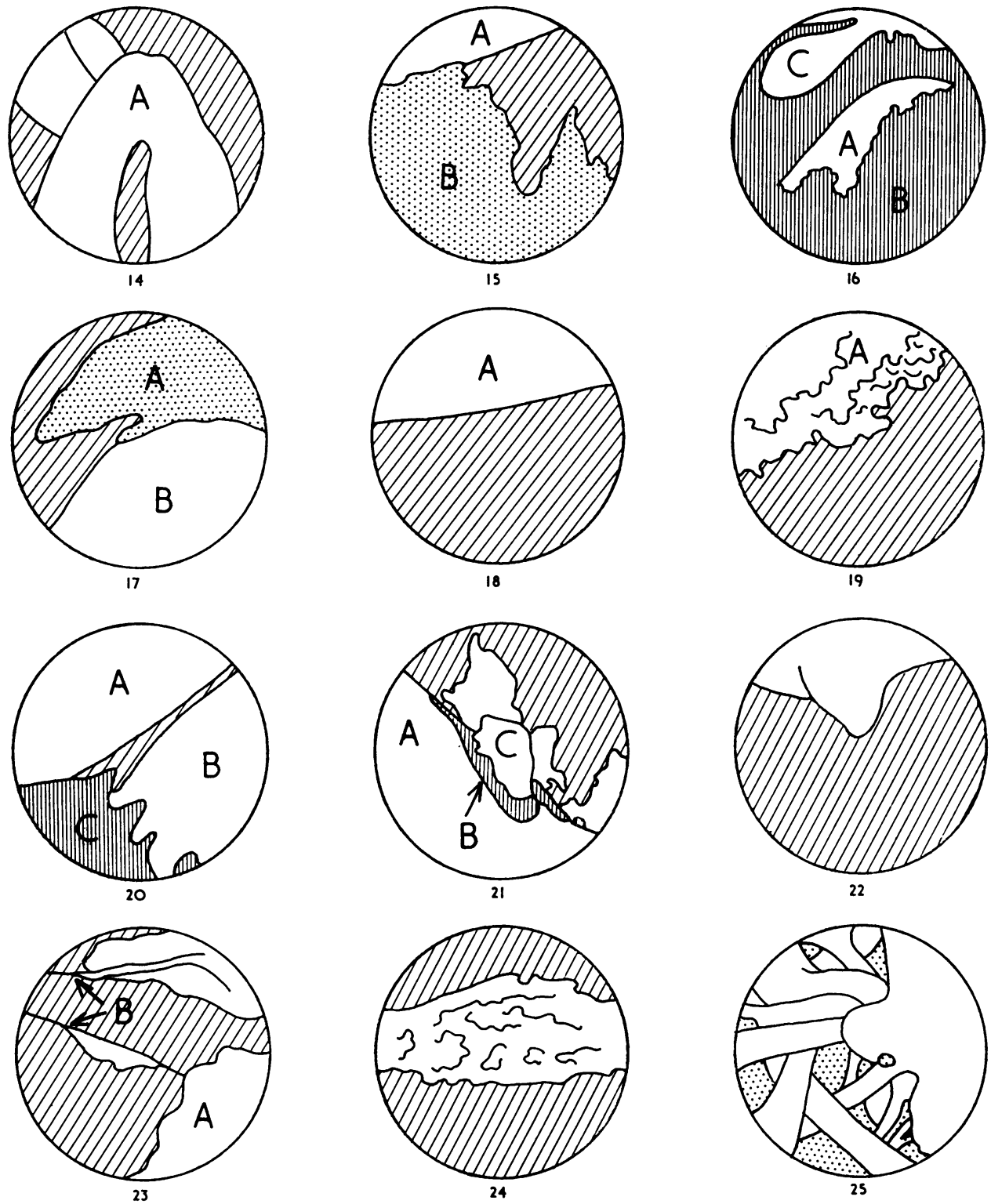

Fig. 14.-Rheumatoid arthritis. Polypi fusing (A) to form bridges.

Fig. 15.-Rheumatoid arthritis. Patellar cartilage (A) overlapped by mass of erythematous hypertrophied synovium (B).

Fig. 16.-Rheumatoid arthritis. Medial tibial condyle (A) with bundles of hypertrophied synovium (B) and fibrin (C).

Fig. 17.-Rhoumatoid arthritis. Pannus (A) spreading over cartilage of femoral condyle (B).

Fig. 18.-Normal cartilage (A) on back of patella.

Fig. 19.-Degenerative changes in cartilage (A) on back of patella.

Fig. 20.-Rheumatoid arthritis. Patello-femoral articulation with roughening of patella (A) and femoral condyle cartilages (B) and early pannus $(\mathrm{C})$.

Fig. 21.-Early rheumatoid erosion. Cartilage (A) on femoral condyle with localized area of pannus (B) and fibrin (C) attached to this superficially.

Fig. 22.-Chondromalacia patellae.

Fig. 23.-Mass of fibrin (A) with connecting threads (B).

Fig. 24.-Band of dense fibrin attached to synovium.

Fig. 25.- Interlacing bundles of structureless fibrin. 
ARTHROSCOPY OF THE KNEE JOINT IN RHEUMATIC DISEASES
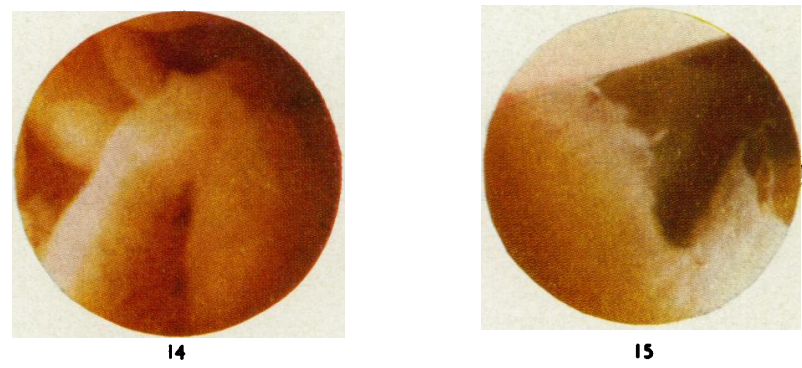

15
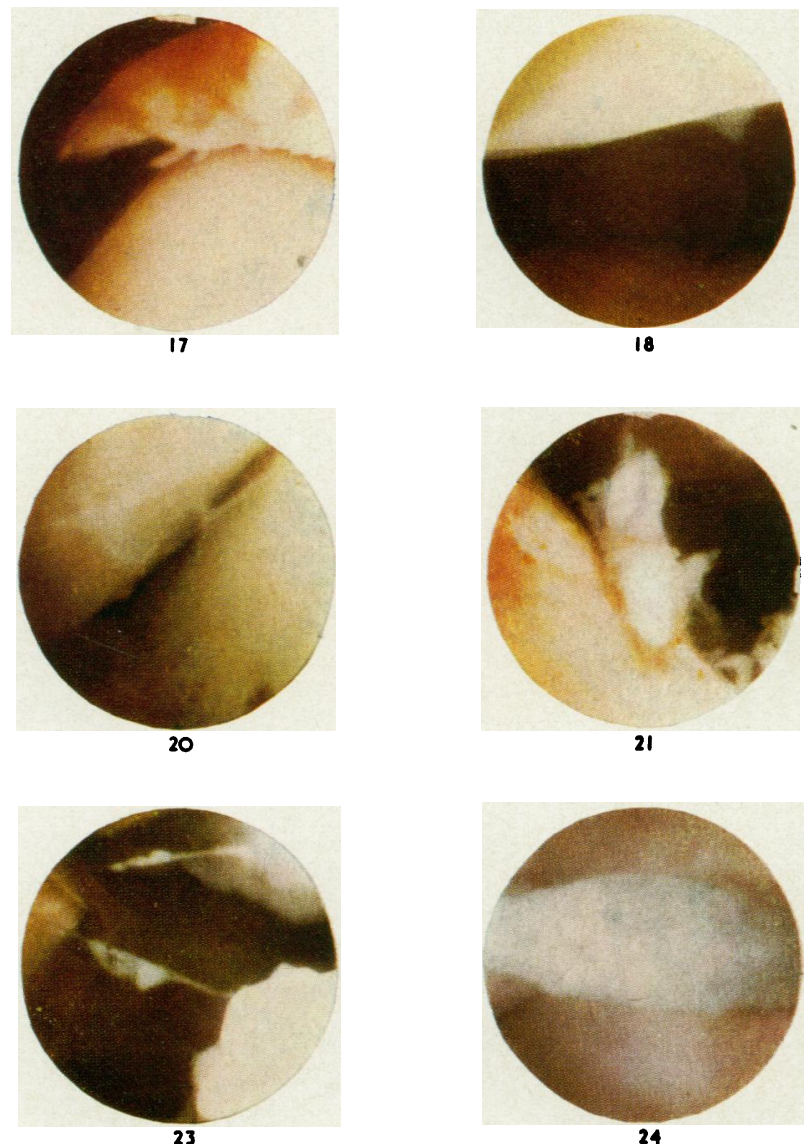

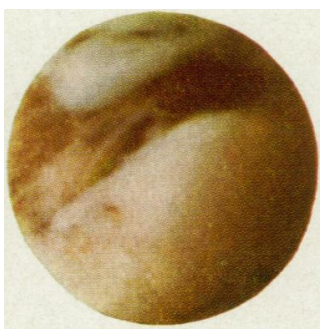

16
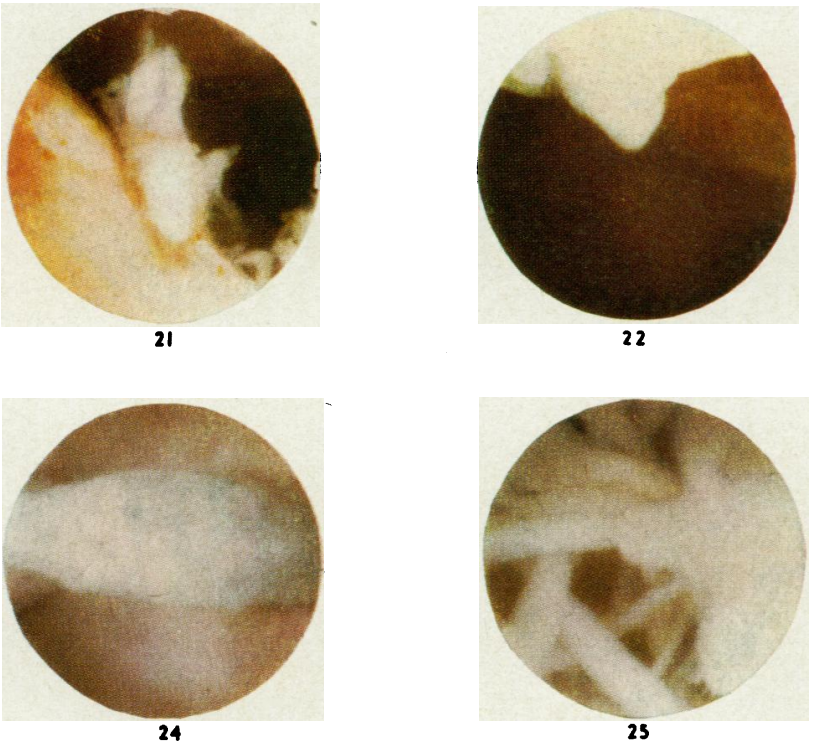


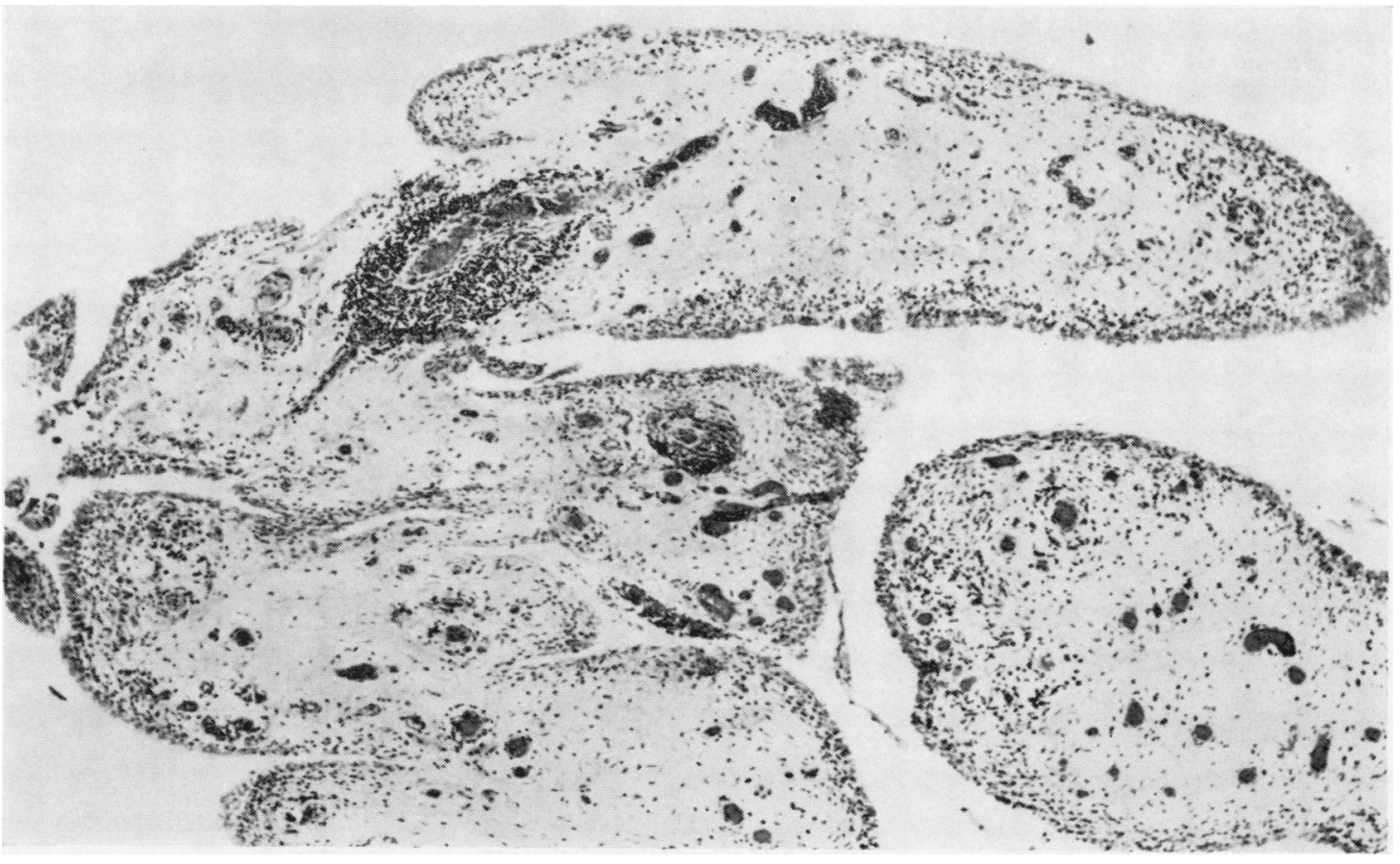

Fig. 26. - Rheumatoid arthritis. Synovial polypi with vascular proliferation and perivascular accumulation of lymphocytes and plasma cells. $\times 25$.

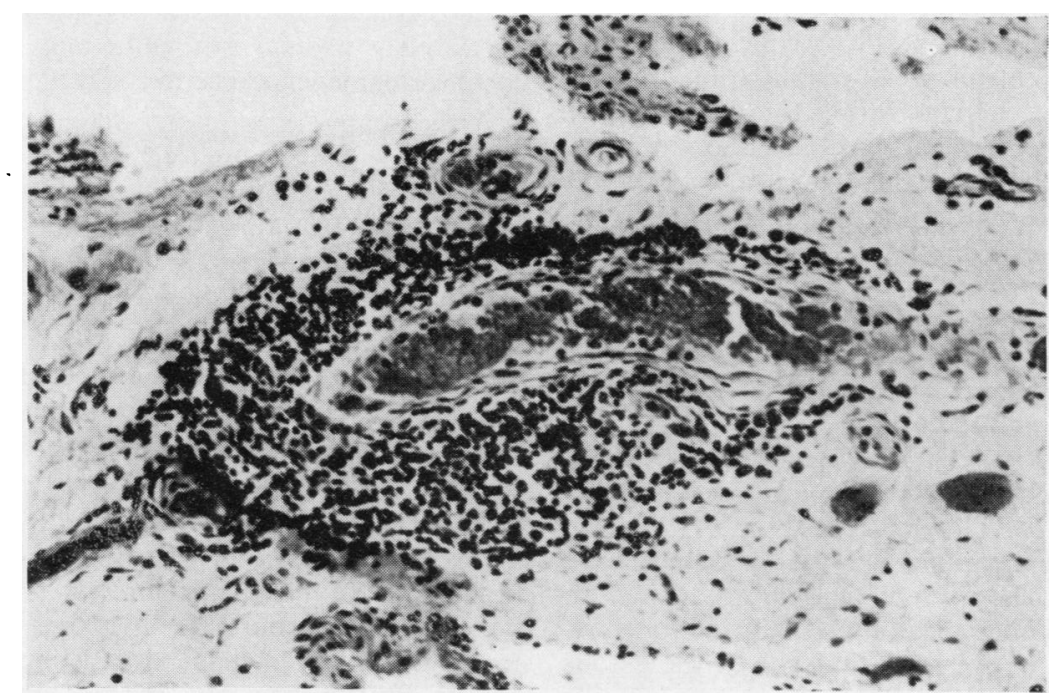

Fig. 27.-Rheumatoid arthritis. Perivascular accumulation of lymphocytes and plasma cells. $\times 80$. 


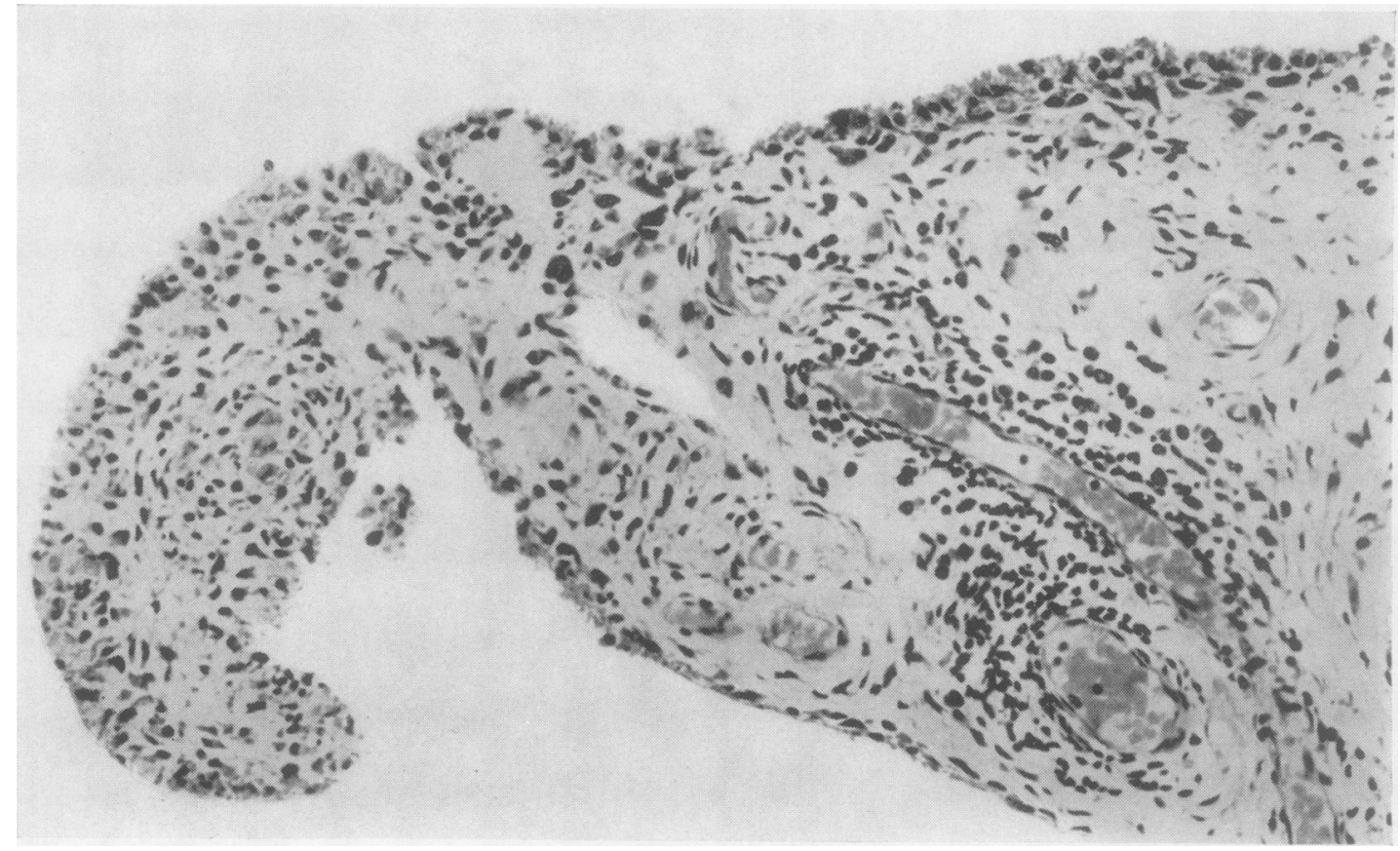

Fig. 28.-Rheumatoid arthritis. Villus with marked plasma cell infiltration especially around capillaries. $\times 200$.

well have different effects on joint structures as compared with less exuberant forms.

The functional state of the joint can be assessed and some idea of synovial hypertrophy obtained by clinical examination. $X$ rays will show changes in the articular cortex and narrowing of the joint space, and blind needle biopsy will provide a specimen of synovium for histological examination. However, pathological changes within the joint may be patchy and important diagnostic areas may be missed. Arthrotomy and open surgical biopsy will provide much information regarding the joint, but requires general anaesthesia, a long incision, and a period of convalescence.

Arthroscopy offers a method of examining the lining of joint. The investigation can be performed under local anaesthesia providing the joint is not acutely inflamed, and the procedure is virtually painless. The patient is able to walk and leave hospital on the following day and no complications have been recorded.

A variety of appearances of the synovium have been recorded. The normal synovium is pale with a superficial vascular anastomosis. In acute rheumatoid arthritis it appears diffusely erythematous and there is later a proliferation of first fine leaf-like villi and later larger coarse polypi. In inactive burnt-out rheumatoid arthritis the synovium again $\stackrel{?}{\rightleftharpoons}$ appears pale and smooth with patchy pigmentation. Long-term correlation of clinical changes with these morphological appearances will provide a much more accurate assessment of the degree of at thritis.

In osteoarthrosis tiny stubbly villi may be found on a relatively normal synovium and the amount of cartilage damage assessed.

Arthroscopy is a useful diagnostic manoeuvre. An unsuspected rheumatoid arthritis or the presence of foreign bodies may be found in patients with unexplained effusions. It was not possible to remove the chondrosis in Patient 5 through the arthroscope as the lesion was too large and fixed.

It has not been possible to view the menisci. This is probably because only local anaesthesia has been used; Watanabe (1967) uses epidural anaesthesia with manipulation of the knee into the ideal position for observing the menisci.

With more accurate biopsy of the synovium an increased precision of histological examination is obtained. Of particular interest are the villi and polypi, which proliferate in active synovitis. The techniques of histochemical and immunofluorescent staining of the specimens should enable much more information to be obtained. 
The arthroscope described above has been used in studying only the knee as its diameter is too large for entering other joints. However, an instrument with a much narrower diameter is being constructed, and it is hoped to extend the scope of arthroscopy to articulations as small as the metacarpophalangeal joints.

\section{Summary}

Arthroscopy offers a safe and simple method of examining the morphology of the synovial mem- brane of the knee joint and of obtaining biopsies under direct vision. The technique is described in detail and typical results are presented.

We thank Dr. R. L. Bishton for examining the biopsies, Dr. W. Harrison for preparing the microphotographs, and Mrs. Susan Kirk for drawing the diagrams.

The arthroscope was purchased with a grant from The Association of Friends of The Royal National Hospital for Rheumatic Diseases, Bath, which we acknowledge with gratitude. One of us (M.I.V.J.) is in receipt of a grant from the Medical Research Council.

\section{REFERENCES}

Barnett, C. H., Davies, D. V., and MacConaill, M. A. (1961). "Synovial Joints: Their Structure and Mechanics", 94. Longmans, London.

Bircher, E. (1922). Bruns' Beitr. klin. Chir., 127, 239 (Beitrag zur Pathologie (Arthritis Deformans) und Diagnose der Meniscus-verletzungen (Arthroendoscopie).

Burman, M. S., Finkelstein, H., and Mayer, L. (1934). J. Bone Jt Surg., 16, 255 (Arthroscopy of the Knee Joint).

Palmer, D. G. (1967). Arthr. and Rheum., 10, 451 (Synovial villi: an examination of these structures within the anterior compartment of the knee and metacarpo-phalangeal joints).

Watanabe, M. (1967). Personal communication.

—, Takeda, S., and Ikeuchi, H. (1957). “Atlas of Arthroscopy”. Tokyo.

\section{Arthroscopie du genou dans les maladies rhumatismales}

\section{RÉSUMÉ}

L'arthroscopie offre une méthode simple et sûre pour examiner la morphologie de la membrane synoviale du genou et obtenir des spécimènes de biopsie sous vision directe. On décrit en detail la technique et on présente des résultats typiques.

\section{Artroscopia de la rodilla en enfermedades reumáticas}

\section{SUMARIO}

La artroscopia ofrece un método sencillo y seguro para examinar la estructura de la membrana sinovial de la rodilla y recoger espécimenes de biopsia bajo visión directa. Se describe detalladamente el procedimiento y se presentan resultados típicos. 